\title{
Editorial
}

\section{The impact of personality and gender on branding decisions}

Journal of Brand Management (2007) 14, 277-283. doi:10.1057/palgrave.bm.2550070

This special issue of six articles addresses the impact that personality and gender can have on branding decisions and reactions by consumers. It also addresses the issue of whether a positive response is associated with similarity or difference between the beholder and producer and further examines the impact of preference on attention span.

The examination of these issues is prompted by the recognition that business survival rests on shaping products or services around the 'unique and particular needs of the customer'. ${ }^{1}$ The activity of envisioning the world as the customer sees it demands an understanding of the part that liking something plays in people's reactions to products. It also demands an understanding of the way segmentation variables such as personality and gender impact on preference aesthetics, the way these interact with production aesthetics and the way finally, these relate to the personality and gender of the creative. This complex chain of interactions is illustrated in Figure 1.

Research on the way segmentation variables impact on and preference aesthetics is still in its infancy and the contributions offered in this special issue cover new ground by examining many of the elements in this chain of interactions.

The focus of this complex chain is the part played by positive reactions to products, with one paper in this special issue, that by Maughan, Gutnikov and Stevens, showing how images that trigger emotions, whether positive or negative, tend to attract more attention. ${ }^{9,10}$ They also indicate that the extent to which attention is a function of positive as opposed to negative emotions is not dealt within the literature.

Fortunately, the young, but established area of research known as 'visual marketing' uses eye-tracking equipment to advance our understanding of these issues. A typical eye tracking session, in addition to gathering information about participants' pupil dilation at a given time, produce raw data specifying where, when and for how long participants' look at elements of a visual stimulus. In the paper by Maughan, Gutnikov and Stevens, a representative sample of participants were shown a slide show containing the stimuli for testing while eye-tracking equipment monitored their eye movements. In a second stage, participants participated in three tests of recall and recognition while in a third phase participants were asked to indicate how much they liked/disliked the stimuli.

The results reported have shown a clear correlation between the number of fixations on an image and subsequent spontaneous and prompted recall of that stimulus. Significantly, post-test questioning revealed that the images which attracted most fixations were those referred to as 'liked'. Thus, on a scale of 1-4 fixations to $20+$ fixations, the per cent of participants who liked an image increased from 47 to 65 per cent. Conversely, the fixations of participants who disliked an 


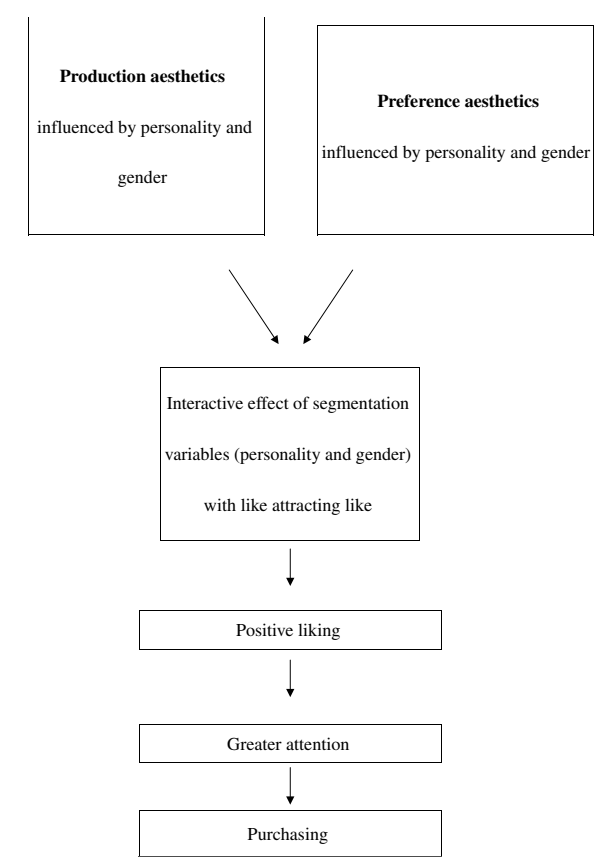

Figure I Web of interactions creating congruence between product and customer preferences

image decreased from 30 per cent to 13.5 per cent. Furthermore, there was a tendency for participants to show better recall of images they had liked than disliked with a constant difference in recall at all three levels measured. In terms of specifics, spontaneous recall for those liking an image was 17.3 per cent and just who disliked an image, it was just 10.3 per cent for those disliking an image. In tests of recall for text as well as for images, the differences in recall between text and images that were liked and disliked was, respectively, 40.7 per cent and 27.4 per cent for text, and 57.5 per cent and 40.1 per cent for images. These results, based on representative samples, are significant in showing a clear correlation between liking, attention and recall of products. As the authors state:

'if a person looks more because they like an advertisement, then marketers should be maximising the likeability of their product or its presentation. This emphasises the need to know and understand the target audience, in particular understanding what they like, and segmenting preference by variables such as age, gender and personality.

In this way, this study establishes a clear correlation between liking a stimulus giving attention to that stimulus and subsequently recalling that stimulus. This finding is consistent with the correction in the research literature between enhanced pleasure and purchasing ${ }^{6-8}$ and clarifies the role of attention in this process.

Given the important link shown here between liking and attention, the rest of the issue is devoted to factors that where to produce product liking. Earlier literature had indicated product satisfaction to be a function of a match between the product and the customer's self-concept ${ }^{2-5}$ and the articles in this special issue explore the complex web of links that bind a product to its creator, on the one hand, and set up a pattern of liking with a beholder on the other. In doing this, they explore the impact of segmentation variables such as personality and gender on the creation of what might be termed the 'production aesthetic' on one hand, and 'preference aesthetic' on the other ${ }^{11}$ are explored in the remaining five papers. Three of these, by alternatively Blythe, Wylie and Harris, explore the impact of personality on the production aesthetic. A fourth by Moss, Hamilton and Neave, explores the impact of gender on production and preference aesthetics. A final paper by Moss explores the interactive impact of personality and gender on production and preference aesthetics and the extent to which, in order to achieve a sense of liking on the part of the beholder/consumer, the segmentation variables that typify the beholder/ consumer need to be matched by those 
of the creator. The imperatives for achieving a match between the segmentation variables of the consumer and the creator flows from the fact that the personality and gender of beholder and consumer may be reflected in their creations and preferences respectively. One of the practical implications from this is the need to employ creatives whose personalities and gender matches those of the purchaser/ end user.

The papers exploring in this issue, the impact of personality and gender on the created work and through this on the production aesthetic, brings into the field of marketing for the first time an area of research that was previously restricted to the Art Therapeutic and Psychological literatures. The papers by Wylie, Harris and Blythe fill this gap by amply demonstrating the extent to which the creator's personality is reflected in the created work, whether through the use made of space, colour, imagery or detail.

Wylie's study involves an examination of the drawings of inmates of a therapeutic prison, showing how a study of these drawings can reveal much about the suitability of their creators' to engage in group therapy. The close correlation that Wylie reports between the art therapist's assessment of suitability (based purely on an assessment of drawings) and that of an independent assessor demonstrates a high validity to the inference of personality from graphic expression. As Wylie writes 'the self is externalised and communicated through creativity'. A number of specific features are used as pointers in the analysis of the drawings. Where colour is concerned, a study assessing the impact of drawing topic on children's colour use concluded that children tend to associate a negative emotion with dark colours as, black or brown while using yellow and orange to convey, with positive happy feelings. ${ }^{12}$
Additionally, where size is concerned, it has been observed that children use size to convey the emotional significance of a topic with appealing figures shown in exaggerated size and potentially threatening figures shown in reduced size. ${ }^{13}$

Moreover, temporal symbolism allows a picture to be read from left to right, from past to future with the present centrally placed. ${ }^{14}$ It offers an X-ray image of the psychological state of the maker such that 'The proportion, perspective, and details in a drawing are general characteristics that can provide information about the functioning of an individual in the context of their expected level of functioning'.(Ibid, p. 25).

Harris's study is similar to Wylie's insofar as it also examines the links between graphic expression and personality. She describes how 80 years of research have made it possible for artist characteristics such as intellectual acuity, developmental maturity, personality, values, attitudes, emotions, behaviour and culture of origin to be inferred from children's artistic works. ${ }^{15,16}$ She then describes empirical work in which she compared interview data regarding 9-10-year boys, with the independent assessments of teachers who based their assessments entirely on an analysis of the boys' graphic expression. Levels of agreement were high with 69 per cent of teachers' comments in agreement with interview data. Only 21 per cent of the teachers' comments contradicted interview data.

These results indicate the extent to which features of personality are mirrored in graphic expression and Harris underlines the importance of her findings by referring to the communicative equivalence of children's and adults' artwork, ${ }^{17-19}$ with similar results across age groups. She also describes the communicative equivalence of design and fine art crea- 
tions, showing how scholars have drawn parallels between design and art for over 70 years.

Blythe's study further considers the effect of the personality on graphic expression, examining this time the impact of personality on the work of advertising agency creatives. They were encouraged to describe the process of creating and interpreting brand personalities, to indicate which animal they most resembled and to say how this linked with their creative work. The creatives were also asked to bring samples of their 'best' work, a task they interpreted as an invitation to bring to samples of their favourite work. This response gave rise to discussion concerning the relationship between the individual and the piece of artwork or communication. The responses highlighted a connection between the personality of the creatives and that of the brand, with the brand reflecting the personality of its creator.

The implication for practitioners, is that creatives will tend to produce work that reflects their own career aspirations, creative impulses, ethics and beliefs. In this way, creatives are likely to produce advertising that appeals primarily to themselves.

In discussing these results, Blythe replaces, the traditional model of communication, described in his paper as 'mechanistic', with a 'pool of meaning' model which highlight the interactive impact of personalities, whether those of the creatives, brand managers, or consumers. In doing this, he moves beyond the traditional model of communications in which 'the effect of personality [is] largely ignored' to a model in which 'part of the dialogue, and part of the development of branding, must involve the personalities of those who develop and deliver the message'. A related finding is that 'crea- tives tend to produce work which they find interesting and stimulating, rather than work which consumers will find interesting and stimulating'. Coupled with the Law of Primacy ${ }^{20}$ this states that earlier communications will take precedence over and colour the interpretation of later communications, Blythe predicts that creatives' preferences will take precedence over consumer preferences. One can see how the creatives' personality can constitute a major obstacle to the achievement of the congruence with end-user preference advocated in the marketing literature $^{2-5}$ This tendency for creatives to produce work that mirrors their own personality could be entirely pernicious were it not for the fact that Blythe shows how clients tend to select agencies and creatives whose brand personalities are congruent with those of the promoted brand.

Whereas Wylie, Harris and Blythe had explored the links between graphic expression and personality, Moss, Hamilton and Neave explore the links between graphic expression (and design in particular) and gender highlighting the impact of gender on the production ${ }^{21-29}$ and preference aesthetic. ${ }^{21,25,26,28}$ In this way, just as a creative's personality leaves its mark on the work created, so too does a person's gender, with the main areas affected being shape, colour, detailing and perspective. Not surprisingly perhaps, in view of the now well-documented impact of gender on graphic expression, is the congruence that appears between the production and preference aesthetics of men and women, with each gender showing a statistically strong tendency to prefer designs produced by people of their own gender. ${ }^{25,26,28}$ This tendency for gender to leave its mark on production and preference aesthetics make it conceivable, as in the parallel case of personality, 
that gender constitutes a major obstacle to the achievement of congruence between the product and the consumer's self-image. An instance of this would be particularly where the gender of the creative and the consumer are not aligned.

The problematic nature of a nonalignment in genders (or at least of a lack of training for creatives in the production aesthetic of a particular gender) is underscored by the notion, presented here for the first time in the paper by Moss, Hamilton and Neave, that many of the differences in men and women's production and preference aesthetics have their origin in evolutionary pressures acting on men and women's visual processes over thousands of years. The weight of the evidence presented here suggests that special efforts may be needed to shift people away from the tendency to produce designs that are typical of their gender. These efforts may include attempts at increasing awareness among managers and creatives of the impact these differences have on educational and professional assessment (eg recruitment of creatives) as well as on the design and marketing of products aimed at males and/or females. ${ }^{24,28}$

The complex interplay of the personalities and genders of creatives and managers on the one hand, and customers on the other, is the subject of the paper by Moss. This shows how achieving congruence between the product and the consumer's self-image rests on mirroring the consumer's personality and gender in the final product. It also rests on overcoming the obstacles that can stand in the way of doing this. The extent to which people are unwittingly subject to the influence of segmentation variables, whether it be personality, gender or nationality, ${ }^{29}$ can lead organisations to recruit people like themselves ${ }^{30}$ and to employ creatives whose values match those of senior staff rather than those of the purchaser or end user. Such a mismatch between internal organisational values and external customer values can unfortunately prevent organisations from achieving the congruence with customer preferences advocated in the marketing literature. Only a concerted campaign of educating organisational internal stakeholders in the value of alternative ways of seeing may enable an organisation to overcome these difficulties.

To conclude, the papers in this issue highlight the obstacles that may prevent organisations from achieving the congruence between product and customer preferences advocated in the literature. These obstacles include preferences on the part of organisational actors that may conflict with those of the target customer, producing HR (recruitment and promotion) and Marketing decisions (selection of branding and designs) that are aligned to the preferences of internal rather than external stakeholders. The existence of these obstacles has been partially highlighted in earlier work ${ }^{11}$ but this special issue affords the opportunity to explore, in detail, the factors that render the achievement of congruence so problematic. These factors include management and leadership constructs that favour the appointment/promotion of personalities and genders that may be at odds with the personalities and genders of the target constituency, leading in turn to the appointment and promotion of creatives whose personalities and genders are at variance with those of the target constituency. Underlying these points is the assumption, amply demonstrated in the papers by Harris, Wylie, Blythe as well as is in that by Mon, Hamilton and Neave, that creative output is highly correlated with personality type and gender. In an era of intensifying competition, delivering 
products that appeal to specific customer segments is a high priority. ${ }^{31}$ Given the importance of the principle of congruence and, within this, the role (demonstrated here by Maughan et al.) of product liking in increasing attention span, the ability to understand and remove obstacles to the achievement of congruence and product liking must be a key priority.

Of course, to understand the roots of a problem is not to final complete solutions. Further work could usefully concentrate on developing the models discussed in this paper so that a more detailed picture is gained of the complex interplay between personality and gender necessary to create the congruence between end user and product advocated in the marketing literature. Future work could also usefully examine and evaluate methods for overcoming a perceived lack of congruence between staff and customer segmentation variables. These methods might include training for $\mathrm{HR}$ and Marketing personnel on the impact of segmentation variables (personality and gender) on production and preference aesthetics, as well as ways of encouraging recruitment and promotion processes that are in line with the preferences of external rather than simply internal customers.

I would like finally, to thank my contributors for participating in this special edition. They are all busy, professional people and I appreciate this response to requests for revisions from myself or reviewers, and meeting the tight deadlines required of this collection. I would also like to thank my Associate Editor, Professor David Farnham, for helping me coordinate this collection, giving me appropriate advice and assisting with the refereeing of the articles in this collection.

\section{Gloria Moss gmoss@glam.ac.uk Guest Editor}

\section{References}

(1) Hammer, M. (1995) 'Reengineering the Corporation', Nicholas Brealey Corporation, London.

(2) Crozier, W. and Greenhalgh, P. (1992) 'The empathy principle: Towards a model for the psychology of art', Journal for the Theory of Social Behaviour, Vol. 22, pp. 63-79.

(3) Brock, T. C. (1965) 'Communicator-recipient similarity and decision change', Journal of Personality and Social Psychology, Vol. 1, pp. 650-654.

(4) Karande, K., Zinkhan, G. M. and Lum, A. B. (1997) 'Brand personality and self concept: A replication and extension', American Marketing Association, Summer Conference, pp. 165-171.

(5) De Chernatony, L., Drury, S. and Segal-Horn, S. (2004) 'Identifying and sustaining services brands values', Journal of Marketing Communications, Vol. 10, pp. 73-94.

(6) Yahomoto, M. and Lambert, D. R. (1994) 'The impact of product aesthetics on the evaluation of industrial products', Journal of Product Innovation Management, Vol. 11, pp. 309-324.

(7) Groppel, A. (1993) 'Store design and experience orientated consumers in retailing: Comparison between the United States and Germany', in Raaij, W.F. van and Bamossy, G.J. (eds) 'European Advances in Consumer Research', Association for Consumer Research, Amsterdam, Vol. 1, pp. $99-109$

(8) Donovan, R. J., Rossiter, J. R., Marcoolyn, G. and Nesdale, A. (1994) 'Store atmosphere and purchasing behaviour', Journal of Retailing, Vol. 70, No. 3, pp. 283-294.

(9) Rosler, A., Ulrich, C., Billino, J., Sterzer, P., Weidauer, S., Bernhardt, T., Steinmetz, H., Fröhlich, L. and Kleinschmidt, A. (2005) 'Effects of arousing emotional scenes on the distribution of visuospatial attention: Changes with aging and early subcortical vascular dementia', Journal of the Neurological Sciences, Vol. 229-230, pp. 109-116.

(10) Nummenmaa, L., Hyönä, J. and Calvo, M. G. (2006) 'Eye movement assessment of selective attentional capture by emotional pictures', Emotion, Vol. 6, No. 2, pp. 257-268.

(11) Moss, G., Gunn, R. and Kubacki, K. (2006) 'Angling for beauty: Commercial implications of an interactive aesthetic for web design', International Journal of Consumer Studies, Vol. 30, pp. 1-14.

(12) Burkitt, E. and Newell, T. (2005) 'Effects of human figure on children's use of colour to depict sadness and happiness', International Journal of Art Therapy, Vol. 10, No. 1, pp. 15-22.

(13) Thomas, G. V., Chaigne, E. and Fox, T. J. (1989) 'Children's drawings of topics differing in significance: Effects on size of drawing', British Journal of Developmental Psychology, Vol. 7, pp. 321-331.

(14) Buck, J. N. and Warren, W. L. (1995) 'HouseTree-Person. Projective Drawing Technique', 
Manual and Interpretive Guide, Los Angeles Western Psychological Services.

(15) Milne, L. C., Greenway, P. and Best, F. (2005) 'Children's behaviour and their graphic representation of parents and self', Arts in Psychotherapy, Vol. 32, No. 2, pp. 107-119.

(16) LaVoy, S. K., Pedersen, W. C., Reitz, J. M., Brauch, A. A., Luxenberg, T. M. and Nofsinger, C. C. (2001) 'Children's drawings: A cross-cultural analysis from Japan and the United States', School Psychology International, Vol. 22, No. 1, pp. 53-63.

(17) Silver, R. A. (1987) 'Sex differences in the emotional content of drawings', Art Therapy, Vol. 4, No. 2, pp. 67-77.

(18) Silver, R. A. (1992) 'Gender differences in drawings:A study of self-images, autonomous subjects, and relationships', Art Therapy, Vol. 9, No. 2, pp. 85-92.

(19) Silver, R. A. (1993) 'Age and gender differences expressed through drawings: A study of attitudes toward self and others', Art Therapy, Vol. 10, No. 3, pp. $159-168$

(20) Lund, F. H (1925) 'The psychology of belief, the law of primacy in persuasion', Journal of Abnormal and Social Psychology, Vol. 20, pp. 183-191.

(21) Moss, G. (1995) 'Differences in the design aesthetic of men and women', Journal of Brand Management, Vol. 3, pp. 51-61.

(22) Moss, G. (1999) 'Gender and consumer behaviour: Further explorations', Journal of Brand Management, Vol. 7, pp. 88-100.
(23) Moss, G. (1996) 'Sex:The misunderstood variable', Journal of Brand Management, Vol. 3, No. 5, p. 296.

(24) Moss, G. (1996) 'Do males and females make judgements in a self-selecting fashion?' Journal of Art and Design Education, Vol. 15, No. 2, pp. 161-170.

(25) Moss, G. (1999) 'Gender and consumer behaviour: Further explorations', Journal of Brand Management, Vol. 7, No. 2, pp. 88-100.

(26) Moss, G. and Colman, A. (2001) 'Choices and preferences: Experiments on gender differences', Journal of Brand Management, Vol. 9, No. 2, pp. 89-98.

(27) Moss, G. and Gunn, R. (2006) 'Some men like it black, some women like it pink: Consumer implications of differences in male and female website design', Journal of Consumer behaviour, $\mathrm{Vol}$. 5, No. 4, pp. 328-341.

(28) Moss, G., Gunn, R. and Kubacki, K. (2006) ‘Angling for beauty: Commercial implications of an interactive aesthetic for web design', International Journal of Consumer Studies, Vol. 30, pp. 1-14.

(29) Moss, G., Kubacki, K., Hersh, M. and Gunn, R. (in press) 'Knowledge management in higher education: A comparison between individualistic and collectivist cultures', European Journal of Education.

(30) Lewis, C. (2006) 'Is the test relevant?', Times, Career section, 30 November, p. 8.

(31) Wesson, T. and De Figueiredo, J. N. (2001) 'The importance of focus to market entrants: A study of microbrewery performance', Journal of Business Venturing, Vol. 16, pp. 377-403. 